experimental hemorrhagic shock models. in : Re cent progress and present problems in the figld of shock, in : Shock ; Federation Proc. Suppl. No.9: 30, 1961.

5) Frank, E. D., Frank, H. A., Jacob, S. W. and/Fine, J., Hepatic blood flow in experimental hemoarhagic shock. Am. J. Physical. 202: 7, 1962.

6) Gregg, D. E., Hemodynamic factors in: shock; Pathogenesis and therapy; Springer, Berlin Göttingen Heidelberg, 1962.

7) Ueda, H., Clinical studies on the liver. J. Jap. Soc. Int. Med. 42: 591, 1953. (in Japanese)
8) Takahashi, S., Studies on anaphylactic shock with special reference to the extravasation of plasma protein and its distribution in the body. Jap. Circul. J. 26: 447, 1962. (in Japanese with English Abstract)

9) Yamamoto, K., Changes in blood pressure and plasma proteins during serum anaphylactic shock. Jap. Circul.J. 25: 427, 1961. (in Japanese with English Abstract)

10) Torii, T., Pathological physiology of anaphylactic shock with special reference to circulatory dynamics. Jap. Circul. J. 26: 503, 1962.

\title{
2. Hepatic Circulation in the Experimental Allergic Hepatitis ${ }^{\dagger}$
}

\section{Yuji Hamamoto and Akimitsu Yoshimi}

[The Department of Pathology (Director: Prof. Y. Hamamoto), Osaka Medical College, Osaka]

$\mathrm{I}^{\mathrm{s}}$ N ORDER to clarify the pathogenesis of microcirculatory disturbances in the liver, hepatic changes of the rabbits were examined morphologically in the intravascular antigen-antibody reaction or anaphylaxis.

Based upon the Hamamoto's theory ${ }^{1 / 2)}$ of "Intravascular Antigen-Antibody Reaction", anti-rabbit red cell guinea pig serum were injected intravenously through the hepatic artery and portal vein of rabbits in the reversed anaphylaxis.

In the active anaphylaxis, shock of the liver was induced experimentally by injecting the bovine erythrocytes into the hepatic artery and portal vein of the previously sensitized rabbits. Erythrocytic antigen were chosen as the most suitable antigen to produce intravascular antigen-antibody reaction, and Yoshimi? ${ }^{\text {?) }}$ has reported on the histological changes in the liver which were induced by this reversed anaphy axis, and the those of the active anaphylaxis were described by Shirasu ${ }^{5}$.

The most severe histological changes in these reactions were as follows: a) parenchymal necrotic foci, b) various degree of degeneration of liver cells, c) serous inflammation, d) thrombosis, e) fibrinoid swelling of arterial walls.

No significant changes were found in the control animals.

For the purpose of clarifying the genesis of these parenchymal necrotic foci and degeneration of liver cells, the fibrin staining were car- ried out. In general the thrombi were found in arterioles and sinusoid surrounding of necrotic foci. The fibrin thrombi in these cases are of a special nature and consist of strands of fibrin, in most instances occluding the lumen of the vessels.

It is suggested that the microcirculatory disturbances occur in this part and these intravascular fibrin deposition in hepatic arterioles is responsible for the necrosis and degenerations.

Then, an experiment was made to investigate these microcirculatory disturbances.

The 2\% trypan blue solution was injected 3 hours after a single provocative injection of antiserum, when permeable activity of the blood vessel walls had been increased most remarkable

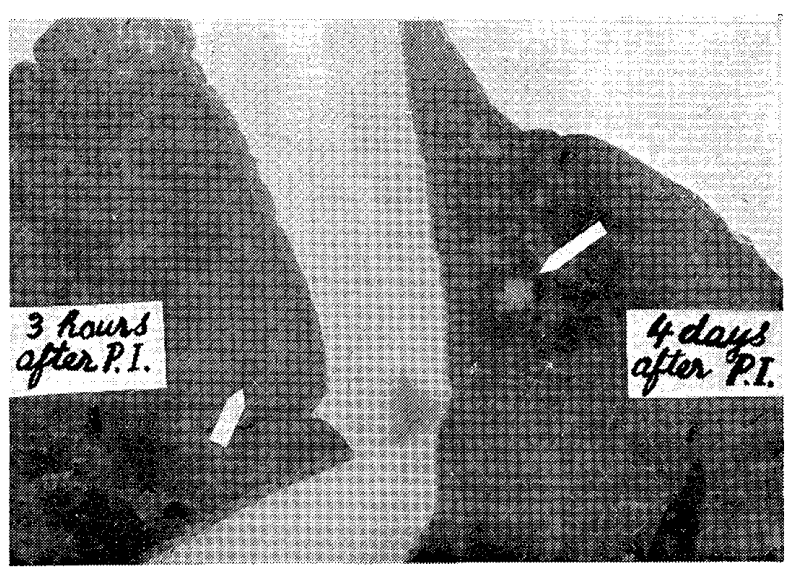

Fig. 1. Showing hepatic changes of the experimental rabbits by injecting the dye after provocative injection (P.I.) of antiserum.

I: Accumulation of trypan blue dye in the liver. (arrow)

$r$ : No accumulation of the dye. (arrow)

\footnotetext{
+ (Received for Publication, July 29, 1963)
} 
TABLE I PERIODIC OBSERVATION OF THE histological ChaNGES IN THE LIVER

\begin{tabular}{|c|c|c|c|c|c|c|c|c|c|c|c|c|c|c|c|c|c|c|c|}
\hline & \multirow[b]{3}{*}{$\dot{8}$} & \multirow[b]{3}{*}{ 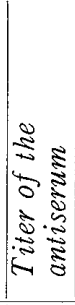 } & \multirow[b]{3}{*}{ 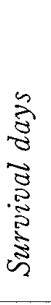 } & \multirow[b]{3}{*}{ 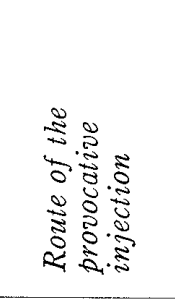 } & \multicolumn{7}{|c|}{ Parenchym } & \multicolumn{7}{|c|}{ Glissons capsel } & \multirow{3}{*}{ 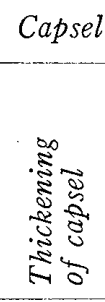 } \\
\hline & & & & & \multirow[b]{2}{*}{ 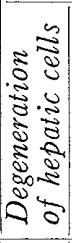 } & \multirow[b]{2}{*}{ 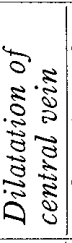 } & \multirow[b]{2}{*}{ 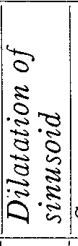 } & \multirow[b]{2}{*}{ 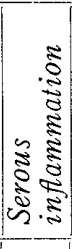 } & \multirow[b]{2}{*}{ 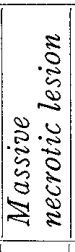 } & \multirow[b]{2}{*}{ 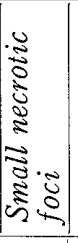 } & \multirow[b]{2}{*}{ 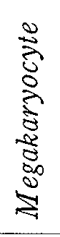 } & \multirow{2}{*}{ 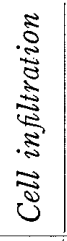 } & \multirow[b]{2}{*}{ 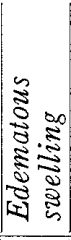 } & \multicolumn{5}{|c|}{ Blood vessel } & \\
\hline & & & & & & & & & & & & & & 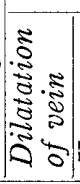 & 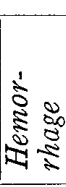 & 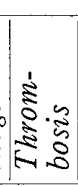 & 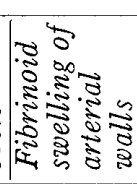 & $\mid$ & \\
\hline \multirow{2}{*}{$I$} & 411 & 32 & 90 & $V \cdot$ portae & + & + & - & -- & + & + & + & + & + & - & - & + & - & + & + \\
\hline & 413 & 32 & 90 & A. hepatica & + & + & - & - & $H$ & + & - & + & + & - & - & - & - & H & H \\
\hline \multirow{3}{*}{$I I$} & 415 & 128 & 60 & A. hepatica & + & + & + & - & + & + & + & + & - & + & - & + & - & + & - \\
\hline & 418 & 128 & 60 & A. hepatica & + & + & \pm & - & - & + & + & + & \pm & + & - & - & - & + & - \\
\hline & 419 & 128 & 60 & $V$. portae & + & + & + & - & + & + & + & + & + & + & - & + & + & + & - \\
\hline \multirow{5}{*}{$I I I$} & 420 & 32 & 40 & A. hepatica & \pm & + & + & - & - & + & + & + & + & + & 一 & + & + & + & - \\
\hline & 421 & 32 & 40 & $V$. portae & \pm & + & + & -- & - & + & + & + & + & + & - & + & + & + & + \\
\hline & 422 & 64 & 30 & A. hepatica & \pm & + & + & - & - & + & + & + & + & + & - & + & + & + & + \\
\hline & 423 & 64 & 30 & A. hepatica & + & + & + & -- & + & + & + & + & + & + & + & + & + & + & - \\
\hline & 424 & 64 & 30 & $V \cdot$ portae & + & + & + & - & - & + & - & + & + & + & - & + & - & - & + \\
\hline \multirow{5}{*}{ IV } & 426 & 64 & 15 & $\begin{array}{l}V . \text { portae } \\
\text { A. hepatica }\end{array}$ & + & + & + & -- & $H$ & + & + & $H$ & H & + & - & + & + & + & + \\
\hline & 427 & 64 & 15 & A. hepatica & + & + & + & - & - & + & + & + & + & + & - & + & - . & + & + \\
\hline & 428 & 32 & 7 & $V$. portae & + & + & \pm & $\rightarrow$ & - & + & + & + & + & + & - & + & + & + & + \\
\hline & 429 & 32 & 7 & A. hepatica & + & + & \pm & - & $H$ & H & + & + & + & + & - & + & + & $H$ & + \\
\hline & 430 & 32 & 7 & A. hepatica & + & + & + & -- & H & $H$ & - & + & + & + & - & + & + & + & + \\
\hline
\end{tabular}

in the inflammatory area. The accumulation of injected trypan blue dye were found in the parenchymal necrotic foci in the liver of rabbits. And also, 2\% trypan blue solution was injected 4 days after the provocative injection of antiserum, when parenchymal necrotic foci had been well developed. No accumulation of the dye was observed completely in the central area of large focal necrosis in the liver, but only microscopically the trypan blue dye was appeared in the sinusoid surrounding the necrotic foci.

In these animal experiments it was noted that hepatic damage could be recognized until 3 hours had elapsed after the provocative injection by promoting permeability of vessel walls, and that it made its development a few days after the provocative injection by formation of fibrin thrombi in arterioles.

Then 15 days after the granulation tissue with the giant cells were seen remarkably surrounding the large area of focal necrosis and fresh fibrosis were developed.

Ninety days after, the major changes were remarkable fibrosis and the liver showed the post necrotic cirrhosis at least in part. But in other part of the liver lobules localized limited inflammatory processes were remained, and the cords of parenchymal cells were somewhat dissociated.

These hepatic changes above described resemble those of eclampsia ${ }^{6)}$ or generalized Shwartzman phenomenon ${ }^{7)}$ and are quite similar to those in the intravascular antigen-antibody reaction, particulary in reversed anaphylaxis.

\section{REFERENCES}

1) Hamamoto, Y., et al., Intravascular Antigen-Antibody Reaction and Similar Reaction. Acta Path. Jap. 8: Supple., 719-733, 1958.

2) Hamamoto, Y., et al., Intravasculäre Antigen-Antikörperreaktion in Verschiedenen Organen. Bull. Osaka Med. Sch. 7: 62-91, 1961.

3) Yoshimi, A., Studies on the Vital Reactions by Anaphylaxis in the Liver. (I) Jap. J. of Allergy 11: 155169, 1962.

4) Yoshimi, A., Studies on the Vital Reactions by Anaphylaxis in the Liver. (II) Jap. J. of Allergy 12: 154$171,1963$.

5) Shirasu, K., Studies on the Allergy Reaction in the 
Liver. Jap. Archives of Internal Med. 7: 811-826, 1960.

6) McKay, D. G., et al., The pathologic anatomy of eclampsia, bilateral renal cortical necrosis, pituitary necrosis, and other acute fatal complication of pregnancy, and its possible relationship to the genera- lized Shwartzman phenomenon. Am. J. of Obst. $\mathcal{G}$ Gynecol. 66: 507-539, 1953.

7) Tsuda, T., et al., Histological Changes of the Liver in the Generalized Shwartzman Phenomenon. Nissin Igaku 47: 360-472, 1960.

\section{Studies on Action of Plasmin upon the Liver ${ }^{\dagger}$}

Sukeo Yamamoto

[The Department of Internal Medicine (Director: Prof. K

$\mathrm{S}^{\circ}$ OME RESEARCHERS have reported that proteolytic enzyme, plamsin, played an irnportant role in releasing of shock agents, and was highly activated in the state of shock or in allergic condition.

The author examined the pathogenicity of plasmin upon the liver tissue.

When plasmin extracted from dog's plasma following Shimizu's method was injected into the mesenteric vein of dog, firstly an ascent of portal vein pressure and then a decent of arterial plessure was observed. [Fig. 1]
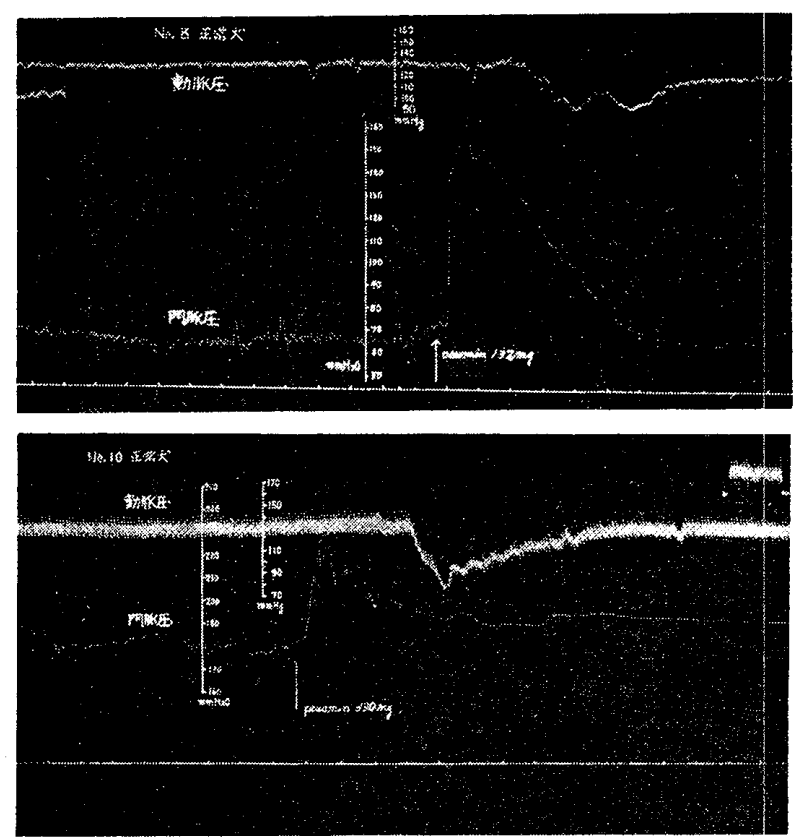

Fig. 1.

When plasmin was injected into femoral vein a descent of arterial pressure was followed by an ascent of portal pressure.

Namely the results showed the same changes of the pressures as were observed in histamintreated animals.
Histopathological examination of the liver was made.

Plasmostasis in the central and portal vein was observed twenty-four hours after the injection of plasmin into the mesenteric vein.

Seventy-two hours after the injection, arterial thrombosis, partial destruction of the arterial wall, epitherial proliferation and swelling degeneration of the vascular wall was observed.

The development of spotty necrosis of parenchymal cells was recognized, but no massive necrosis was produced with the plasmin.

Under the electron microscope dilatation of

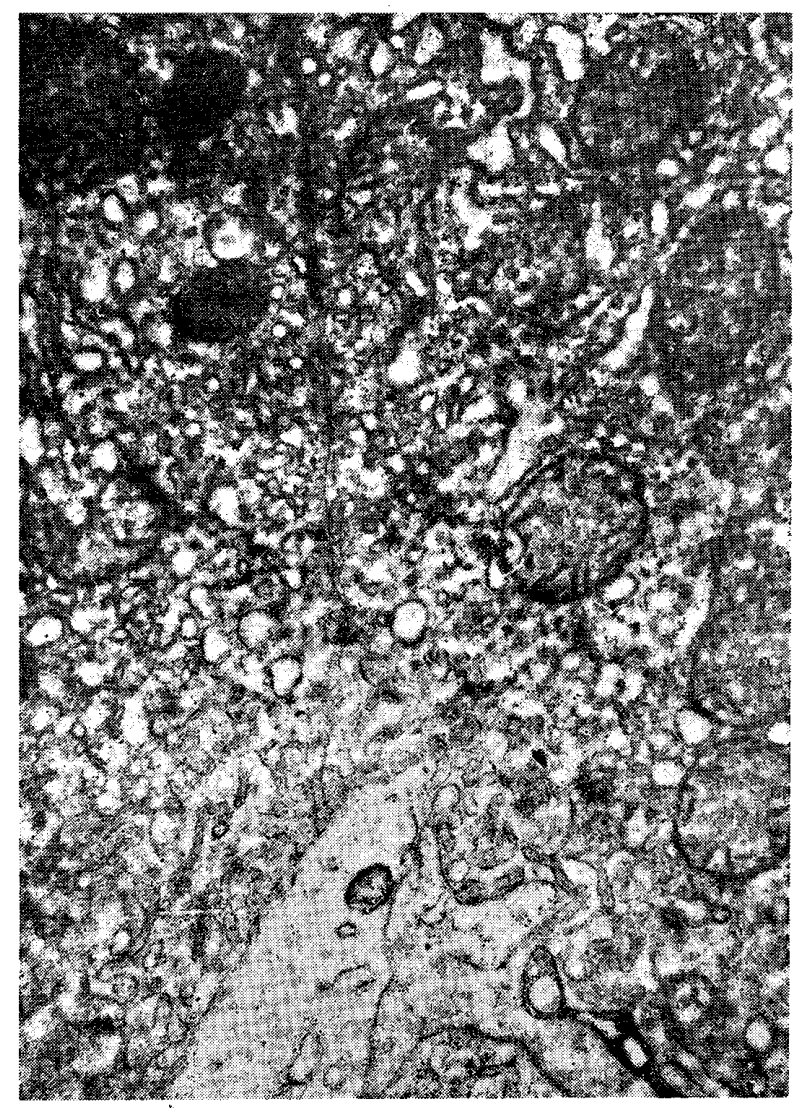

Fig. 2.

+ (Received for Publication, July 29, 1963) 